\title{
Actual Factors Efficiency in the Sphere of Art Management: Remote Control Specifications
}

\author{
A. V. Gudkov* \\ Glinka Nizhny Novgorod State Conservatoire, Nizhny Novgorod, Russia \\ *Corresponding author. Email: midk2008@yandex.ru
}

\begin{abstract}
The article is devoted to one of the functions of management in general and art management, in particular, control. The main aspects of control are considered in detail: the desired result, the complexity of control procedures for the manager and subordinate, the advantages and disadvantages of choosing various objects of control, the procedure for choosing a schedule of controlling actions, the nuances of delegating control powers to the relevant authorities, choosing the depth of control, and others. The types of controlling actions and their specificity for art management are described in detail. Attention is focused on the features of remote control and its differences from office control. The author comes to the following conclusions: It is very important to document and record all control procedures and criteria. These documents (regulations, norms, procedures, rules, etc.) should be correctly and consistently communicated to employees. In the process of implementing all control procedures, it is necessary to understand that the negative attitude of employees towards him is natural. It is necessary to form a positive perception by the employee of control, based on an understanding of the necessity and importance of control procedures. A manager, before implementing control algorithms, must realize its importance for the organization and the need to allocate special time for it. Control must be timely, and its methods are varied. An organization that has well-established controls is more expensive and works more efficiently.
\end{abstract}

Keywords: factors efficiency in the sphere of art management, control specifications, art management.

\section{INTRODUCTION}

At the beginning of the twentieth century, Henri Fayol identified 5 management functions that remain unshakable and undoubtedly relevant to this day: accounting and control, planning and forecasting, analysis, coordination and regulation. The function of control is distinguished by him as one of the most important not by chance, because the very profession of a manager was introduced by Frederick Winslow Taylor primarily to define a special employee who does not produce goods and services, but is engaged in the coordination and control of production and workers [1].

In modern conditions, it is the control over remote employees that is especially relevant, since external factors force business interactions to become more and more separate. Traffic congestion, the need for employees who speak a different language and live in another region, country, continent, pandemics and epidemics, touring musicians, writers, art critics or composers traveling the world with lectures and creative meetings are just a small part of the factors affecting convenience and even the need to move to remote interaction with employees. Even rehearsals of theater and musical groups are often advisable to be carried out remotely, and the so-called "Digital Theater" is gaining more and more popularity in the world, the peculiarity of which is that it is not just broadcasts of performances on the Internet, but projects originally conceived for online [2]. Even modern researchers of the "theory of small groups" are making adjustments, and the well-known experiment with a hall, into which many people are launched, wait an hour and take pictures showing that people are united in so-called "small groups", obviously, needs to be developed, updated and complication and, possibly, extrapolation in the case of remote interaction of the participants in the experiment [3]. So, let's consider the specifics of working with a remote employee.

\section{MATERIALS AND METHODS}

Firstly, any manager needs a positive approach to the business and psychological qualities of a subordinate. All employees should be considered good by default, but it should be understood that each of them interprets the word "good" in its own way. Each employee has his own criteria for the optimal performance of work, and therefore the autonomy of an employee should be considered a synonym for "lack of control", that is, the 
tendency to make their own decisions, which can lead to a result that was not planned or even to a dead end, that is, to a lack of result. This leads to an urgent need to create a discipline in a remote team, most often to the documentation of the rules of conduct for home during working hours, because if the manager does not know, that an employee is doing at home, he does not know, that the employee does in the office. It is control that can and should provide discipline in the team, and that, in turn, returns attention and focuses it on the performance of work. It must be understood that the struggle for the attention of an employee at home is much more difficult than in the office, since at home he has much more temptations (family, dining table, TV, Internet, books, etc.).

One of the main problems of control is the wrong and untimely reaction to violations of the activities of employees. Moreover, the reaction is both managerial and psychological, such as, for example, suppression of the "impostor syndrome" inherent in art workers [4], that is, the conviction that the place occupied in the organization is undeserved, the tendency to underestimate their achievements and incorrect assessment of the high results obtained. ... For such employees, control should not be too strong, because in a situation "the boss sees everything" the employee can "break down" and drastically worsen work efficiency. The illusion may arise that this thesis contradicts the well-known Elton Mayo rule, but it only complements it. Mayo's Rule is as follows: A scientist experimented with ergonomics with female workers in a sewing workshop, increasing the illumination of workplaces and measuring changes in labor productivity. Mayo found that it had increased and decided to decrease the illumination and re-evaluated the productivity. Paradoxically, in this case, too, it increased again. This experiment made it possible to conclude that labor productivity was mainly influenced not by the improvement of the ergonomics of the production process, but by the very fact of the manager's attention to the personnel [5]. Control is a method of obtaining a predictable result, and it must be used effectively.

One of the main specific properties of the Art management process is that the manager is often faced with the problem of controlling employees, who are much better specialists in their narrow field of activity. The most effective way to improve the quality of control and management in general is to constantly deepen the knowledge of the manager in this specific material and technical part of the work process. For example, if an art manager directs musicians, then he himself must increasingly become, if not a musician, then a critic with a deep understanding of the process. Otherwise, such an important part as "micromanagement" disappears from the management process [6]. However, there is another side of micro-control: it is impossible for micromanagement to lose the vision of the interaction process of the entire system as a whole, because control over the life of the entire system is the primary task of effective management.

\section{RESULT}

Consider the desired outcome of the control process. It should be understood that the product of any control is the corrections made, and preferably in a written, normative form. Consequently, the absence of adjustments indicates, if not the absence, then the low effectiveness of control. From this, an important conclusion can be made about the required frequency of control. It must first of all correspond to the "price of the game" [7], that is, the risk of obtaining a negative result. For example, if you did not control whether the artist learned his role, and he studied another text for a week, then there are two possible scenarios for the development of the situation: in the first case, the loss of the production process will amount to the actor's salary per week, if it is possible to rehearse another scene, and in the second case, the weekly salary of the entire cast, the cost of renting the stage, the theater's utilities and so on, if without this learned and worked out text, rehearsals are impossible. If the losses in the first case are not critical, then control over the remote activities of this actor once a week can be considered acceptable, while in the second case, losses from lack of control are significant and should be carried out much more often. It should also be borne in mind that control itself has a cost and, as a rule, is quite high, since usually the time of the leader is the most expensive in the company. With this in mind, it is necessary to follow the main rule: the more control, the better.

Let's estimate the complexity of control for a manager. Firstly, control causes problems, which increases the number of tasks for the manager, hence the increase in control proportionally increases the total volume of the manager's work. Define, what is the problem. A logical statement of the form "Given - Must be obtained - Solution method" is the definition of a problem, where the solution is the result of applying the method. If the solution method is not defined, then the problem is the problem, and if there are no initial conditions ("Given"), then in logic it is called a problem situation.

It follows from the above that the more often an employee turns to the manager, the more problems he has to solve. Effective in this case is seen the introduction of a special "protocol problem situation", ie a set of steps that an employee who is faced with the problem that has to do, before treating her to the head. For example, in the theater, if an actor has some problem with the role, then the following set of actions can serve as such a protocol:

- Search for a solution in the literature, on the Internet 
- Recording your performance on a camera and then viewing it with an analysis of what you saw

- Seeking help from more experienced colleagues

- Formation of several different options for solving the problem

In this case, if the problem is still not resolved, contacting the manager should begin with a step-by-step description of the actions defined in the protocol. In turn, the manager from this appeal can draw conclusions about:

- $\quad$ The competence of the employee, his qualifications

- $\quad$ Competence of those employees to whom the first one turned for help

- Team relations, psychological climate

Secondly, control often leads to conflict situations, and the leader must be psychologically ready for this. In a conflict, several rules must be observed [8]:

1. Always ask a specific question

2. Ask a question only about the workflow (it is unacceptable, for example, the transition to the employee's identity)

3. Only reply to a specific question (for example: to the question "Why did this month, I was deprived of the award?" Is not necessary to tell the story of the company, to enumerate all, who once had been deprived of awards, etc. It is necessary to explain why it was decided that's what specific solution).

4. Talk about what does not suit the leader and what will happen for it. It is worth noting that it is permissible to do this only once, since if the leader shows that the punishment is situational, not obligatory and can be avoided, then this will negatively affect the discipline in the team and, as a result, the quality of control.

5. "It is better to think badly of employees and make mistakes than to think well of them and make mistakes" [9].

Thirdly, any control error - is, generally speaking, the financial loss for the company. And since most of the control functions cannot be delegated, any control error is a manager's mistake.

Fourthly, it should be understood that the employee's miscalculations associated with a lack of control on the part of the manager are the manager's fault, not the employee's. If, for example, an employee constantly works uncontrollably with significant amounts of money, then he has an extremely high "corruption capacity" and in the case of appropriation of a part of the money, the blame for this applies to the manager who has not organized sufficient control.
Let us now estimate the complexity of control for a subordinate. Firstly, the employee is afraid of revealing his dishonesty, and sometimes he is afraid of it even if it is not there. Often there is a situation of psychological rejection, especially in the case, if the control introduced suddenly, before he was gone, and the employee does not understand why it is happened. It is necessary to explain in detail to the employees why the new actions were introduced. Paradoxically, more often than not, the more control, the better the attitude of employees towards it. And, as a result, their attitude towards the leader is better.

Second, the employee is afraid of unfair criticism. The so-called "Seagul-management" [10] should be avoided, this is, as a rule, a negative characteristic of management activities in which the leader "swoops in on the problem how", shouting loudly, making noise, and then just as rapidly and suddenly "flies away", leaving behind chaos and disorder that other employees "rake". You should also avoid a situation where the leader has a reputation as a person who is always dissatisfied with something and will not back down until he finds something to criticize. It is very important that the subordinate always understands the logical causal relationship between the work done and the criticism.

Thirdly, the employee always seeks to get rid of control, to sabotage it. This is both a working and a psychological property of any subordinate, logical and explainable. Nobody likes to be controlled. It should be understood that just as a vaccine, being unpleasant in itself, can save you from health problems in the future or even save a person's life, so control can save an organization from losses or even preserve its existence.

\subsection{The Specifics of Remote Control and its Difference from Office}

Firstly, in the remote mode of operation, the so-called "background" control is extremely difficult. This is a type of control that is carried out by the head "against the background" of the main activity without interrupting it. For example, passing by the vocalist rehearsing the role, the leader can make adjustments "on the fly", look for the correctness of his movements or the emotional coloring of the segment. This is an extremely effective and simple form of control that allows you to make adjustments in the current mode, usually verbally.

Secondly, "random" control becomes extremely difficult. It is very similar to the background one, but differs from it in purposefulness and possible planning in the manager's schedule. In this case, it is recommended to use a random number generator, since any other random control can be calculated by employees, they can adapt to it, as students in a school adapt to a teacher who calls on the journal those who have to answer homework at the blackboard (if there are many grades, then most likely they will not ask, if they have already answered, 
they will not be called a second time, etc.). A random number generator (procedure Randomize (..) in programming languages) allows you to get rid of the problem of "calculating" checks by employees.

Thirdly, remote employees - it is always a communicative complexity. Often it is impossible to understand whether the subordinate has fully understood the task, whether he correctly understands how to solve it.

Fourthly, it becomes difficult to access the current results of the workflow. Most often, it is impossible to check what the employee is doing right now. For example, a musician studying a new piece may answer the question "what are you doing now?", but he will not be able to show the exact state of his working process.

Consequently, fifthly, the remote worker has a much wider field for manipulation. For example, an artist or designer who did not complete the work can come up with a lot of excuses for this: from "the cat ruined the canvas" to "the electricity was turned off and all the files were deleted". It is extremely difficult to verify the veracity of this.

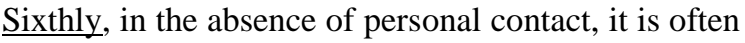
impossible to understand the psychoemotional response and reaction of the interlocutor, to evaluate the effectiveness of criticism, possible excessive harshness, resentment. For example, actors working on a role are often in a psychologically very vulnerable state and even the slightest comments can plunge them into depression, despair or apathy. And if during personal contact there is always the opportunity to apologize, shake hands, drink tea together, etc., then when working remotely, the manager may not notice the negative effect of the corrective remark.

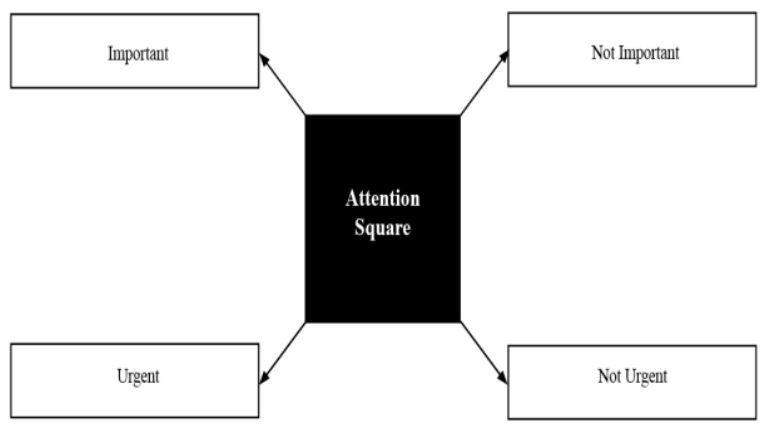

Figure 1 Types of control actions

\subsection{Types of Control Actions}

An important condition for control should be the absence of automatism in it, but only consistency, step by step and specificity. Let's consider various types of control actions and assess their advantages, disadvantages and applicability to the work of remote employees.

\subsubsection{Regular}

Activities performed at specific intervals, such as once a week, month, or year. The most famous type of such control is exams. The main advantages of such control are the clarity and certainty of the criteria and the ability to assess the speed of their work and the percentage of completion of the planned work, to speed up themselves, or vice versa, to increase thoroughness and scrupulousness. Among the disadvantages of such control can be noted the ability to adjust the results to the test conditions, and not to the true quality criteria. For example, it is known that passing an exam and truly indepth knowledge of a subject are two different things. Without the second, the first is impossible, but on the contrary, it is quite possible.

\subsubsection{Selective}

This is the control of individual samples of the workflow or the activities of individual employees from the general group and the extrapolation of the results of their work to the entire work or all employees, respectively. For example, when an orchestra is practicing a piece of music, you can test several random passages with random musicians and, based on the results of the test, conclude that all the work has been completed. Or, when an art gallery receives a series of paintings from a previously verified supplier, you can selectively check the authenticity of several paintings and, based on the verification, draw a conclusion about the authenticity of the entire batch.

At the same time, for well-established employees, control can be carried out less often (for example, check not 5 pages of the text learned by the musician, but one). But there is a danger of overlooking the error and encountering a phenomenon called the "broken window effect". Just like at a non-residential building, behind one broken window, if it was not repaired, the others will gradually break it, so an employee who made a mistake that went unnoticed will do it again and again, and other employees will follow him. [11] ...

You should also remember the rule formulated by Dan Kennedy: "All horses are destined to lame sometimes" [12]. This means that no matter how well an employee has worked up to this point, he always has the possibility of an oversight. Therefore, even the best employees should not be left completely unattended. It is common for any person to optimize their work in terms of effort, labor costs, reducing them to the optimal ratio "I do less - I get more". One of the control functions is to prevent the employee from reducing labor costs to the detriment of quality and productivity. 


\subsubsection{Point Control}

This is the control of several intermediate points in the production of finished products. For example, an artist must show all etudes before transferring them to a large canvas, or show a graphic sketch before applying paints. The specifics of such control is that checkpoints should be set at a frequency corresponding to the number of marriages in the works which is suitable to the head. It should also be understood that this type of control is particularly costly because it is constant and therefore needs constant optimization. For example, if the site has shown itself to be perfect, then the control point can be removed from it.

\subsubsection{Random Control}

This is the above control using a random number generator. One of the properties of human thinking is the constant search for patterns. If there are a lot of employees, and there is a regularity of control, then they are more likely to find it than the manager will hide it. Using a randomizer will make the problem of finding patterns unsolvable, since these patterns do not exist. Such a random number generator can be any "household" randomizer, such as a coin toss, a dice, a top with an arrow, etc.

\subsubsection{Specific Control}

This is a special individual control method for supervalued employees ("stars"). For example, a great actor is used to working on a role while in the bathroom at 2 a.m. This is the only way he tunes in correctly and plays brilliantly. It is necessary to give him the opportunity to work in the most comfortable conditions, without depriving him of control, change the way of control to suit his specifics. This is a method that is characteristic, practically, only for the field of Art management. Such control should be carried out only by the leader himself, or, if he does not have sufficient authority, he can delegate it to someone who has this authority, for example, a mother, wife, close friend or professional psychologist-motivator. Otherwise, you can cause an extremely negative effect, demotivate the employee ("Who are you to tell me how to work!?").

This control should be as delicate as possible, psychologically verified and applied in isolated cases. It is often especially costly, as it uses a lot of the manager's resources, especially his time.

\subsection{Selection of the Object of Control}

Let's consider what is most effective to control and what is the specifics of changing the points of application of actions.

\subsubsection{Statistics Control}

The specificity of this control is as follows: statistics are not always relevant, that is, a statistical indicator does not always reflect the quality and nature of work. For example, let's say that we have a device that shows how many keys a pianist presses on an instrument during a given period of time. A high value of this indicator will not be evidence of the fact that he is playing exactly the program that he should, but if he does not press the keys, then we can definitely know that he is not playing the piano. This implies the main rule for controlling statistical indicators: an action does not guarantee a result, but the absence of an action always shows the absence of a result.

\subsubsection{The Quality of the Work Performed}

Verification should include compliance with regulations. Therefore, if there is no regulation for this type of work, then it is necessary to introduce it. For example, safety precautions when conducting an excursion. If the viewer stood on the edge of a cliff and fell down, injuring his leg, then in the presence of his signature in the document on safety, the wine completely falls on him, while in the absence of such a document, the guide is to blame and, as a result, the head of the excursion organization. Consequently, the art manager is a priori considered to be guilty of the poor quality of the work of the employees, if he did not convey to them the requirements of the quality regulations.

\subsubsection{Motivation of Workers}

An important rule should be understood: the knowledge of employees does not bring added value, it is their skills and abilities. For example, a pianist may be an excellent musicologist and know great about solfeggio, but this will not improve the quality of his concert if he is not good enough as a performer. "The Tchaikovsky Competition is won not by theorists, but by the performers" [13]. The quality of skills is usually checked in the survey mode, but the questions brought up for it should be correctly formulated and have the character "Can you do this?", And not "Do you know how it is done?". If an employee cannot get the job done, then it doesn't matter how well-grounded he is theoretically.

\subsubsection{Quality of Management Processes}

This is the control of managers of the second level and below. Experience, vision of the structure of the process, action are checked. For example, the producer controls the director, set designers, screenwriters. The spent budget, understanding of prospects, technologies, etc. are checked. 


\subsubsection{Discipline}

In this object, the main rule is that control helps to ensure discipline, but that discipline itself is not control. For example, it is known that creative people are often not disciplined, but if there is collective work (performance, orchestral performances), then a strong motivation for discipline is necessary. An example is the famous myth of one great performer who was at home while the audience filled the hall, waiting for his concert. The assistant warns him that there is an hour left before the concert, and the car is waiting for him at the entrance. The musician tells him that there is enough time, he will be in time for the concert. Then half an hour passes, 45 minutes, 50 - the answer of the maestro is the same. Then he says that he will not go anywhere, the concert breaks down, with all the ensuing consequences.

\subsection{Purpose of Control Actions}

The main product of any control should be the adjustments made. Specifically, adjusting employee behavior may include:

- Motivation and impact on it

- $\quad$ Education and training

- $\quad$ Sanctions and Punishments

It should be understood that on an individual basis or even when interacting with these methods on small groups, this impact has a very low efficiency, since it has a temporary effect, because an employee can quit or move to another job, perform new functions. Consequently, organizational changes such as creating a training document, changing regulations, introducing a new instruction, etc. will be more effective. It is easier to influence a specific employee, but the result will be much less noticeable. If a manager notices that an employee does not know or understand something, then a quality manager should see this as an organizational, systemic problem. You can, for example, film the dialogue with him on camera and make a training video, which will become mandatory for all employees to view. It will also be effective to create a test for understanding the problem and induce the whole company to pass it [14].

The product of effective control is also organizational changes, expressed in the adjustment of existing regulatory documents. If the plan is not implemented, the manager must correctly understand what is the reason for this. If it is in the ineffective work of employees, then it needs to be corrected, but the reason may also be the incorrect setting of tasks. If the implementation of the existing plan bears too high costs, then it should be adjusted or completely abandoned the implementation of the plan. For example, if learning a new piece of music for an orchestra is too difficult or inconvenient for musicians, then sometimes you should abandon this piece and during this time learn several others.

The next result of control is a change in expectations or plans for the future. They should also be documented and communicated to all employees.

In the process of any control, it is very important to collect materials and information for further training of employees, marketing and advertising. This is why an effective art manager needs a control schedule.

\subsection{Control Action Schedule}

Mahatma Gandhi wrote: "If you want to change the world, start with yourself. "The internal resistance of the head to the work on changing the regulations, the schedule, the inclusion of control in it is much worse and more dangerous than the resistance of employees to this process. Therefore, first of all, the leader must start with himself in this. By including controlling actions into his schedule, he can correct those that he missed and allocate specific time for them in his task planner. Time management specialists [5] consider the optimal allocation of $10-25 \%$ of the manager's time to carry out control measures. At the same time, control tasks must be prescribed in advance, knowing them in advance. The most important rule should be understood: The cost of an organization with well-functioning control is much higher, which means that by making effective control actions, the manager creates added value both for the object of control and for the entire organization as a whole.

In time management, the concept of a square of attention has been introduced. This is a structure like:

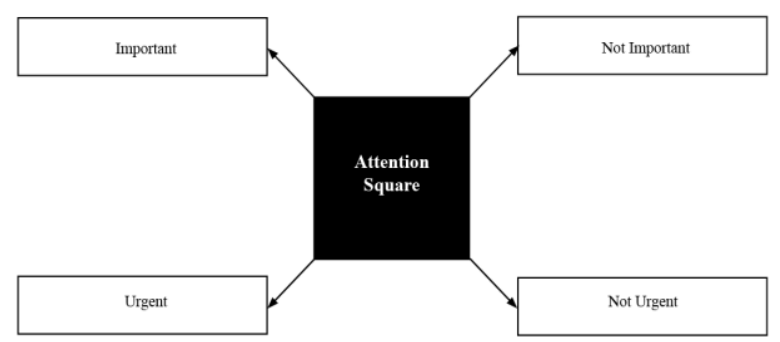

Figure 2 A square of attention

If, for example, the manager devotes 8 minutes per hour to regular control, then this activity in the square has the status "Important - not urgent", but if the manager has not done this, then the task automatically switches to the "Urgent" status. For example, in art management, a random mode of current control is carried out. Questions are asked:

- What task are you currently working on?

- What have you already done, at what stage are you?

- What are the difficulties?

- What ideas and perspectives arise? 
- What can you demonstrate so far?

For example, a producer asks a composer, who is creating music for a play or movie, questions about what stage is the writing of music in and what can he show now? In the event that a phone call with such questions is made for the first time, this can shock the performer of the work and lead to a stupor. In this case, it is necessary to treat such a reaction with understanding, but in the future he will be additionally motivated and better prepared. Also, such actions increase corporate efficiency, because the employee understands that his work is important and increases his inner sense of importance for the organization, self-esteem.

\subsection{Depth of Control}

As mentioned above, micromanagement is an extremely effective control tool, since the leader penetrates deeply into the activities of employees. But in this case, it is necessary to understand that it is more correct not to motivate, but to teach. The manager shouldn't be nitpicky, but should constantly look for opportunities to make organizational changes.

\subsection{Delegation of Control Authority}

In some cases, it is advisable for the head of the control functional link to transfer some of his functions to other subdivisions. At the same time, it is necessary for them to understand the standard so that they have a clear vision of the sample to which they should strive and with which the obtained result should be compared. Therefore, one should be confident in competence and empower these regulatory bodies with the power and tools for making local organizational decisions. Here again we run into the problem of having written instructions. If they exist, then it is possible and necessary to delegate control powers, otherwise only the manager himself can exercise control. Control is:

- Observation

- Comparison

- Decision-making

- Realization

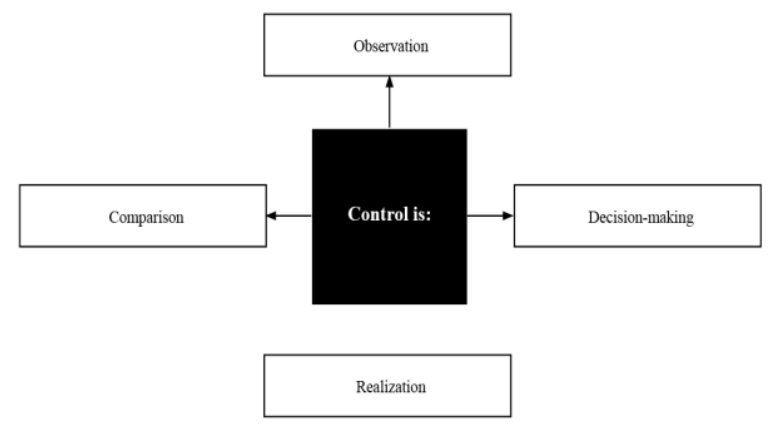

Figure 3 Control
It is dangerous to delegate all these functions, since there is a risk of loss of vision of the error that has arisen in the process. But you can assign functions separately. Delegation of the functions of decision-making and its realization seems to be especially risky, since the responsibility for these stages is greatest. Observation and comparison can be delegated in the event that the standard is prescribed by the regulations.

Regulatory authorities and the staff should be as competent to be able to analytically evaluate, what happened: regulation failure, or imperfection. The leader, however, must constantly pay attention to the activities of the regulatory authorities, especially during their training.

\section{DISCUSSION}

As noted above, any employee always has an internal rejection to any control, especially to its changing and deepening. However, a high-quality manager must find the resources to convey to the employee the understanding of the need for such influences. It is necessary to delicately generate an understanding that times and market competition are getting more complicated, that the purpose of control is not the dismissal of an employee, but its verification (but if it turns out that the employee is too incompetent, then his dismissal is inevitable). You should also make it clear that changes in the market must occur quickly and in a timely manner, because the slower the organization reacts to the market, the more competitive advantages it loses and the greater the losses it incurs.

It is very important to observe the rule of no retroactive force in decision making. First, an instruction is written and only from the moment it is delivered to the team, there is control over its implementation and sanctions for non-performance are introduced. The most correct procedure for introducing control is to first discuss it with each employee personally, so that he understands the need for this process and does not have a feeling of surprise and his low corporate importance. This is followed by discussion and conclusion of an agreement with him on the depth of control. And only after these actions can you change the regulations for the entire organization. For example, in the art-field, employees should be informed of the danger of a decrease in the attendance of a performance, an increase in competition for the viewer from other theaters, changes in the conditions for providing a venue, or the customer's doubts about which performance to keep in the repertoire.

The orchestra also needs an understanding of high competition. But in no case should you tell the employee that "we have a lot of people who want to take your place", since in this case there may be two options for a response: excessive fear or rejection (unwillingness to 
work, apathy, aggressive reaction-strike). Any of these outcomes will lead to a decrease in productivity, whereas control should increase it.

One of the most convenient modern methods of monitoring remote employees is digital "cloud" services [15]. It is necessary to oblige employees to keep all intermediate documents in the access of the manager. For example, a composer, writer and arranger create performance material. Everything written, composed and mixed must be stored in a common "cloud" and at the end of each working day to make a short oral or written report on the work done. It should include answers to two critical questions:

- What has been done?

- What has not been done, for what reason and when will it be done?

It should be noted that such reports are effective only if the manager has time in the schedule to check them. If you have enough time, you can deepen your control by implementing a detailed hourly plan and its implementation. But if the manager is not ready to check such reports in sufficient detail, then it makes no sense to overload employees with them. The compromise is to selectively call employees and ascertain from them what and when they did, what is the result and how does it compare with the plan? For example, the study of a new piece of music by an orchestra. If a musician, according to the plan, was supposed to spend 1 day studying the agreed part of his party, but spent a week, then the leader can raise a question about the competence of this employee.

\section{CONCLUSIONS}

Before motivating employees to control, the manager himself must realize several important rules:

Losses of the company are not only various types of damage for the manager, but also deprivation for his family. Reducing control entails a decrease in the organization's profits, and, consequently, the leader will spend less money on loved ones and on his life outside the business. This means that the car will be worse, the rest will be more modest, the apartment will be smaller, etc.

With insufficient or no control, a business can cease to exist. Control can be compared to the playing of an orchestra without a conductor: it seems that everyone plays their part, but together the mechanism does not work harmoniously.

In conclusion, it should be noted that it is very important for an effective art manager to determine the optimal amount of verification. Redundancy, like not enough, can have negative consequences for an organization. In the first case, there may be an overload of the number of tasks in the manager's schedule, and in the second, a decrease in the quality of employees' work.

\section{REFERENCES}

1. A. Fayol, «General and industrial management», Management is science and art, Respublika, Moscow, Russia (1992). DOI: https://doi.org/10.30936/2227-79512018-10-25-37.

2. Meduza, «Performances in zoom and votsap How digital theater is born in quarantine - and how it is better than broadcasts of ordinary productions» (2020). https://meduza.io/feature/2020/05/10/spektakli-v-zume-ivotsape. DOI: https://doi.org/10.17759/langt. 2018050201

3. Y. Kolominsky, Psychology of relationships in small groups, TetraSistems, Minsk, Belarus. DOI: http://doi.org/10.5281/zenodo.165453.

4. M. Labkovsky, I want and I will. Accept yourself, love life and become happy, Alpina Pablisher, Moscow, Russia (2018). DOI: https://doi.org/10.31874/2309-1606-201924-1-154-173.

5. E. Mayo, The Social Problems of an Industrial Civilisation, Routledge, London, United Kingdom (2007).

DOI: https://doi.org/https://doi.org/10.25146/1995-0861-201844-2-69.

6. H. Chambers, My Way or the Highway: The Micromanagement Survival Guide, Berrett-Koehler Publishers, San Francisco, USA (2004). DOI https://doi.org/10.17223/15617793/434/9.

7. R. Strongin, Operation research. Models of economic behavior, Nizhny Novgorod, Russia (2002). DOI: https://doi.org/10.21684/2411-197X-2018-4-2-84-94.

8. M. Labkovsky, I want and I will. Accept yourself, love life and become happy, Alpina Pablisher, Moscow, Russia (2018). DOI: https://doi.org/10.31866/2617 2674.2.1.2019.170873.

9. S. Perevedentsev, Video lecture "Control" (2018). DOI: https://doi.org/10.21146/2413-9084-2019-24-1-7-45.

10. T. Bradberry, «The cost of seagull management». In: Industrial and Commercial Training, 41(3) (2009) pp. 139-141. DOI: https://doi.org/10.21146/2072-0726-202013-4-89-101.

11. J. Wilson, G. Kellin, «Broken windows», The Atlantic Monthly (1982). DOI https://doi.org/10.21146/20720726-2018-11-3-15-165.

12. D. Kennedy, Tough management. Get people to work for results, Alpina Pablisher, Moscow, Russia (2014). DOI: https://doi.org/10.21146/2413-9084-2021-25-2-5-8. 
13. F. Taylor, Principles of scientific management, Kontrolling, Moscow, USSR (1991). DOI: https://doi.org/10.24411/2346-8408-2018-10002.

14. S. Perevedentsev, Video lecture "Control" (2018). DOI: https://doi.org/10.1016/j.sbspro.2014.12.563.

15. Datami, «Basic security rules for using cloud data storage» (2020). https://datami.ua/ru/bezopasnostoblachnyh-hranilishh-i-tehnologij-osnovnye-pravila/. DOI:https://doi.org/10.31874/2309-1606-2018-23-2192-218. 